\title{
A Pluralist Account of Knowledge as a Natural Kind
}

\author{
Andreas Stephens
}

\author{
Preprint \\ The final publication is available at Springer via: \\ http://dx.doi.org/10.1007/s11406-016-9738-3
}

\begin{abstract}
In an attempt to address some long-standing issues of epistemology, Hilary Kornblith proposes that knowledge is a natural kind the identification of which is the unique responsibility of one particular science: cognitive ethology. As Kornblith sees it, the natural kind thus picked out is knowledge as construed by reliabilism. Yet the claim that cognitive ethology has this special role has not convinced all critics. The present article argues that knowledge plays a causal and explanatory role within many of our more fruitful current theories, diverging from the reliabilist conception even in disciplines that are closely related to cognitive ethology, and thus still dealing with knowledge as a natural as opposed to a social phenomenon, where special attention will be given to cognitive neuroscience. However, rather than discarding the natural kind approach altogether, it is argued that many of Kornblith's insights can in fact be preserved within a framework that is both naturalist and pluralist.
\end{abstract}




\section{Introduction}

KNOWLEDGE IS IMPORTAnT to us both in our daily life and in science. However, philosophical investigations and discussions regarding how we ought to view knowledge have been going on for millennia without clear results, often following a historical split between those focusing on internal aspects, such as Bonjour (1985) and Chisholm (1988), or external aspects, such as Dretske (1981) and Goldman (1986). Similarly, many philosophers nowadays would consider themselves to be heeding some form of naturalism, although finding a generally approved naturalistic approach is difficult. Naturalism has instead been interpreted and promoted in many different forms, from the pragmatism of Peirce (1877), James (1907) and Dewey (1938) to the eliminative materialism of Dennett (1996) and the Churchlands (1998).

In Knowledge and its Place in Nature (2002) Hilary Kornblith presents a naturalistic epistemological theory, based on cognitive ethology, according to which knowledge should be seen as a natural phenomenon and a natural kind requiring reliably produced true belief. I view Kornblith's theory as a promising candidate for a fruitful naturalistic epistemology, but his choice to use cognitive ethology as his sole scientific base for knowledge will be shown to be problematic. I will argue that the theory can remain a fruitful option if it is revised in the direction of pluralism.

This article will begin with an analysis of Kornblith's naturalistic epistemology, starting in section 2 where I will present an outline of Kornblith's theory and discuss it in an attempt to elucidate as many relevant aspects as possible. Section 3 will examine a crucial flaw in the theory, regarding Kornblith's choice to solely focus on cognitive ethology as the only science relevant as a base for knowledge. In section 4 the role of knowledge in cognitive neuroscience is presented, as a contrast to Kornblith's focus on cognitive ethology. In section $5 \mathrm{I}$ will investigate how pluralism, in the context of science, affects Kornblith's theory and present an additional claim that, in my view, saves the theory from the aforementioned flaw while still remaining true to Kornblith's initial stance, followed by a suggested revision of the theory based on this claim in section 6 . In section 7 a short summarizing conclusion is offered.

\section{Kornblith On Knowledge}

Kornblith (2002) argues that many traditional epistemological theories are misconceived. The base for this argument is encapsulated in the following claim: 
(1): "[... T] he subject matter of epistemology is knowledge itself, not our concept of knowledge." (Kornblith, 2002, p. 1)

Since the traditional epistemological focus often is on our intuitions about, or concepts of, different phenomena rather than on the phenomena themselves, most theories can, according to Kornblith, be seen as changing the subject altogether. An investigation into what people think about a phenomenon, rather than into the phenomenon itself, might be an interesting, yet distinct, task in its own right (Kornblith, 2002, pp. 1-4, 163).

Kornblith's claim points out the possible discrepancy between how the world $i s$, and how the world is believed to be. It is his view that the world governs truth and falsehood regarding what knowledge is, rather than any intuitions a subject may or may not harbor. If there is a phenomenon of knowledge, then our considerations about it are largely irrelevant for an investigation of the phenomenon. Kornblith does acknowledge a role for intuitions, yet views them as inferior to theoretical understanding. Intuitions, often stemming from background knowledge or folk beliefs, can be useful in the beginning of a philosophical or scientific investigation, for example by highlighting particularly salient cases, but only until there is better theoretical understanding available, in which case intuitions should give way for empirical investigation. ${ }^{1}$

Where traditional philosophical discussions often focus on intuitions regarding imaginary problems, paradoxes and counterfactual situations, Kornblith's theory affords them merely a preliminary role:

"Intuitions must be taken seriously in the absence of substantial theoretical understanding, but once such theoretical understanding begins to take shape, prior intuitive judgments carry little weight unless they have been endorsed by the progress

1 Siegel (2006) criticizes Kornblith for the role he ascribes to intuitions, which he views as question begging. I will grant that Siegel has a point here, although I think that Kornblith's discussion can be seen as offering enough material to answer it. In my view, the issue Siegel raises hinges on whether or not one accepts the stance Kornblith promotes in his third claim. As I interpret Kornblith's argument, he is aware that his line of reasoning demands an acceptance of naturalism. Made evident in his argument and possible to see in formulations such as: "From a naturalistic perspective, there are substantial advantages to looking outward at the phenomena under investigation rather than inward at our intuitions about them." (Kornblith, 2002, p. 16, my italics). What Kornblith wants to do, as I understand him, is not to convince someone who is a firm non-naturalist that he or she has to accept that theoretical understanding trumps everyday intuitions, but rather give a plausible explanation of what role intuitions (can) fill in a naturalistic theory. So the question Kornblith discusses is that given a naturalistic stance, what role can intuitions play? The question begging that Siegel accuses Kornblith of seems to stem from an interpretation of Kornblith's intentions that is not entirely correct or charitable. 
of theory. The greater one's theoretical understanding, the less weight one may assign untutored judgment. [...] Thus, appeal to intuition early on in philosophical investigations should give way to more straightforwardly empirical investigations of external phenomena." (Kornblith, 2002, pp. 14-15)

I interpret Kornblith's position on this matter as possible to summarize into a second claim:

(2): Theoretical understanding trumps intuitive judgment, so intuitions should give way to theoretical understanding based on empirical investigations of external phenomena.

Given this initial discussion, a promising epistemological approach is thus to explore actual cases of knowledge, or other relevant phenomena, using the best theoretical understanding available, rather than to investigate what someone happens to find intuitively plausible in a hypothetical situation, at least this is Kornblith's view on the matter.

\subsection{Distinct Epistemological Questions and Naturalism}

According to Kornblith, epistemology should be closely connected to science. However, importantly, epistemology is an autonomous discipline vis-à-vis science since epistemological questions, given their often normative status, frequently differ from scientific questions. So, the questions epistemologists pose ought to be considered legitimate and proper objects of investigation, rather than discarded for being non-scientific. This means that while Kornblith accepts a rather traditional ontological naturalism, where physical reality is seen as containing nothing "supernatural," he does have a characteristic interpretation of how methodological naturalism should be construed (see, e.g., Papineau, 2015; Rysiew, 2016). Kornblith is, in my view, best described as endorsing a form of cooperative naturalism where epistemologists are allowed to investigate all questions they deem relevant, but need to take scientific findings into account whenever there is theoretical understanding available (Rysiew, 2016). So, epistemologists should work with results from science, and also within the boundaries set up by science. The situation can be compared to how, for example, chemistry is constrained by physics, or biology by chemistry (Kornblith, 2002, pp. 26-27). This means that Kornblith, given his insistence to ground his theory in science, endorses a form of naturalistic epistemological stance: ${ }^{2}$

${ }^{2}$ Kornblith does not elaborate on his version of naturalism, but rather takes it for granted. 
(3): Philosophical investigations ought to adopt a cooperative naturalistic stance.

Although (3) is my interpretation of Kornblith's theory, not something that is openly stated in his text, I believe that the claim is close to Kornblith's view. It is this stance that motivates his approach to philosophy and epistemology. ${ }^{3}$ A similar interpretation of Kornblith's theory can be found in Goldman (2005):

"Hilary Kornblith's Knowledge and Its Place in Nature has many interesting things to say about what knowledge is and isn't, but its core theses concern meta-epistemology, more broadly, meta-philosophy. Naturalistic epistemology is fundamentally a methodological thesis; it takes a stance on how epistemology should be conducted. Specifically, it holds that epistemology is or should be, in whole or part, an empirical rather than an a priori affair. Kornblith embraces the stronger variant, which says that the subject should be wholly empirical, and this idea is extended to philosophy in general. The book consists of Kornblith's distinctive rationale for this methodological thesis, coupled with many lines of response to naturalism's critics. $[\ldots$ T] he core of the book is his detailed program for naturalistic epistemology (and philosophy)[...]." (Goldman, 2005, p. 403)

It should be noted that this is not to imply that Kornblith thinks that epistemology, or philosophy, should be taken over by science, which would be a replacement naturalistic stance, made famous by Quine (1969). According to most interpretations of Quine's classic essay, epistemology is subsumed under cognitive psychology (Quine, 1969, p. 82). Since Kornblith's naturalism differs from Quine's, his theory does not face the difficulties that for example Kim (1988) raises for Quine's theory, i.e., that Quine is changing the subject to a focus on causal, rather than justificational, relations (see also Rysiew, 2016, section 3.1). Even though Kornblith also has a focus on causal relations, he acknowledges the normative and distinct questions epistemology raise (Kornblith, 2002, p. 138).

Kornblith also opposes substantial naturalism - the view that the questions epistemologists pose should be re-formulated in strictly scientific terminology - and instead sees epistemological questions as legitimate, nonreductive and in need of answers in their own right (Kornblith, 2002, pp. 26-27, 171-172; see also Rysiew, 2016).

\footnotetext{
3 To put Kornblith's ideas in context and perspective it might be illuminating to briefly mention that some more or less similar ideas, can be found in for example Maddy (2007) and van Fraassen (2002), who highlight that philosophy should adopt a scientific attitude - a stance. However, both Maddy's and van Fraassen's theories differ from Kornblith's on crucial points.
} 


\subsection{Knowledge as a Natural Phenomenon and Cognitive Ethology}

Kornblith argues that to motivate an investigation into any phenomenon, that phenomenon must have a theoretical unity to it. It must be possible to distinguish it from other phenomena. Kornblith argues that knowledge is such a phenomenon:

"There is a robust phenomenon of human knowledge, and a presupposition of the field of epistemology is that cases of knowledge have a good deal of theoretical unity to them; they are not merely some gerrymandered kind, united by nothing more than our willingness to regard them as a kind. [...] Now one of the jobs of epistemology, as I see it, is to come to an understanding of this natural phenomenon, human knowledge." (Kornblith, 2002, p. 10)

I will extract two claims from the above quote:

(4): Human knowledge is a natural phenomenon.

(5): The natural phenomenon of human knowledge has a good deal of theoretical unity.

Kornblith points out that the phenomenon knowledge is, in fact, empirically investigated in science:

"One of the more fruitful areas of such research is cognitive ethology. There is a large literature on animal cognition, and workers in this field typically speak of animals knowing a great many things. They see animal knowledge as a legitimate object of study, a phenomenon with a good deal of theoretical integrity to it. Knowledge, as it is portrayed in this literature, does causal and explanatory work." (Kornblith, 2002, pp. 28-29)

I interpret Kornblith's view regarding that cognitive ethology uses knowledge as a causal and explanatory category as an essential claim for his theory:

(6): Knowledge plays a causal and explanatory role within one of our more fruitful current theories - cognitive ethology.

It now becomes important for Kornblith to show that human knowledge is rightly treated as a form of animal knowledge rather than as separated in kind, since Kornblith sees and uses cognitive ethology as the science to investigate both:

"[...] I will also argue that human knowledge is not different in kind from the knowledge to be found in the rest of the animal world. Indeed, I will argue that the kind of knowledge that philosophers have talked about all along just is the kind of knowledge that cognitive ethologists are currently studying." (Kornblith, 2002, pp. 29-30) 
This can arguably be summarized into a seventh claim:

(7): The kind of knowledge that is used in cognitive ethology is also applicable to humans.

It should, however, be noted that there is an ongoing debate regarding anthropomorphism and whether human cognition should be viewed as different in kind or in degree compared to other animals - something Kornblith acknowledges and discusses (Kornblith, 2002, pp. 43-48). Kornblith argues that human knowledge should be seen as a form of animal knowledge, at most differing in degree. To motivate his view Kornblith discusses how intentional terminology is widely used in cognitive ethology literature and research, and that it is even necessary to capture some aspects of animal behavior. Intentionality is hence necessary to understand animal behavior according to Kornblith, since descriptions of animal behavior without intentionality merely become descriptions of bodily motions (Kornblith, 2002, p. 33). Furthermore, animals seem to need some form of understanding and representation to function in their environment:

"The environment places certain informational demands on an animal. If it is to satisfy its biologically given needs, it will need to recognize certain features of its environment and the evolutionary process must thereby assure that an animal has the cognitive capacities that allow it to deal effectively with that environment. What this requires is the ability to represent information." (Kornblith, 2002, p. 37)

The situation described in the above quote makes it possible to attribute mental representations and beliefs to animals as well as humans since it is necessary to make reference to both beliefs and desires to predict both human and animal behavior (Kornblith, 2002, p. 42). These aspects can only be fully captured by the intentional terminology used in cognitive ethology:

"There are commonalities among animals that can be captured at the level of talk of belief but cannot be captured in any lower-level vocabulary. [...] So when we look at a bit of animal behavior, one question we need to ask is whether its explanation requires talk of informational content, or whether some lower-level explanation, whether chemical or otherwise, will do." (Kornblith, 2002, p. 41)

Kornblith gives examples of cognitive ethologists who do ascribe intentionality to animals, and indeed some cognitive ethologists do view human and animal knowledge as similar in kind in Kornblith's sense. However, arguments against Kornblith's claim are more plausible than Kornblith is willing to acknowledge. The current state of research suggests that neither view that human and animal knowledge are relevantly similar or dissimilar - can be ruled out (see, e.g., Klopfter, 2005, pp. 204-205). Some issues might 
ultimately only be possible to settle after a strict definition of key terms, although just how these should be defined might be a matter of theoretical preference and only pushing the problem one step back. If one adopts Kornblith's view, humans are animals among others, and knowledge is a natural phenomenon that humans share with other animals, in which case the differences between human and (other) animal cognitive abilities are just a matter of degree.

Nonetheless, many experiments reach conclusions strengthening the view of human uniqueness, as discussed by Shettleworth (2013, pp. 23-25, 8588; see also Klopfer, 2005, pp. 204-205), among others. Both Shettleworth and Klopfer point out that since many animals have cognitive and sensory abilities that differ a great deal from humans, it might be a mistake to draw too far-reaching conclusions about their similarities (Shettleworth, 2013, p. $18)$.

Wynne (2007) does however point out that most modern ethologists are aware of the risk of anthropomorphism and take this into account in their investigations. Kornblith argues that as long as the fruitfulness of his view trumps other concerns, such as a fear of anthropomorphism, it can be seen as the right approach. Wynne, in the end, is skeptical and fears that anthropomorphism leads to folk-psychological influences that have no scientific relevance (Wynne, 2007, p. 134).

According to Kornblith it is possible to make a distinction between animal knowledge and human knowledge, since many demarcations are theoretically possible, but it would not mark any significant difference (Kornblith, 2002, p. 73). ${ }^{4}$ Further aspects of animal and human knowledge can be made evident by examining how self-conscious reflection is generally thought to be a central aspect of knowledge - especially human knowledge (Kornblith, 2002, p. 103). This theme is elaborated on in Kornblith (2012) in which a more thorough discussion of the topic is carried out. An important point that is highlighted is that introspective justification is often lacking and to a large extent is unreliable, which makes it problematic to let it play any major role in our view on the nature of knowledge. Rather than having a transparent

\footnotetext{
${ }^{4}$ Both Kusch (2005) and Bermúdez (2006) question Kornblith's argument against a division between human and animal knowledge, since they claim that even unreflective knowledge - in humans - have aspects of logical reasoning built into it. This should, according to Kusch and Bermúdez, be seen as a genuine difference, which Kornblith downplays or ignores. I will regard it to ultimately be an open issue, in that there are arguments both for and against a division. So both interpretations of cognitive ethology and the usage of knowledge regarding animals and humans are reasonable, and the issue is in itself hence not enough to pose any real problem for Kornblith's theory.
} 
mind, we largely rely on processes beyond our self-conscious, or introspective, grasp. Since many theories of knowledge mark introspection or reflection, in some form, as necessary for - or at least a virtue of - knowledge, this seems to imply that either two forms of knowledge will be needed to meet the different demands, or that different forms of justification need to be accepted to cover all perspectives of the phenomenon of knowledge. Kornblith ultimately argues that introspective reflection and differences in cognitive capacities are non-successful in demarcating human from animal knowledge.

\title{
2.3 Knowledge as Natural Kind
}

Natural kinds are, according to Kornblith, to be seen as homeostatically clustered properties, forming a stable unity or a 'well-behaved category' (Kornblith, 2002, pp. 61-62). The natural phenomenon knowledge, as instantiated in specific humans or animals, is the locus of such a homeostatic cluster of properties:

\begin{abstract}
"I want to claim that knowledge is, in fact, a natural kind. [...] I take natural kinds to be homeostatically clustered properties, properties that are mutually supporting and reinforcing in the face of external change. [...] The knowledge that members of a species embody is the locus of a homeostatic cluster of properties; true beliefs that are reliably produced, that are instrumental in the production of behavior successful in meeting biological needs and thereby implicated in the Darwinian explanation of the selective retention of traits." (Kornblith, 2002, pp. 61-62)
\end{abstract}

From this I condense the following claim:

(8): Knowledge is a natural kind.

Bird and Tobin (2012) describe a natural kind as "[...] a grouping or ordering that does not depend on humans." (Bird and Tobin, 2012), so natural kinds should hence be seen as real groupings in nature, independent of what anybody thinks about them. And if one is a scientific realist, as Kornblith is, an investigation using the categories provided by science is the best method there is for understanding what constitutes a natural kind. This is similar to how Kornblith reason concerning the irrelevance of intuitions, and stem from a similar approach, focusing on a phenomenon in nature rather than on people's impressions or intuitions of that phenomenon. So even though a specific scientific theory might be erroneous, there is a fact of the matter concerning the phenomenon. Some traditional examples, often used to show specific natural kinds, are water or $\mathrm{H}_{2} \mathrm{O}$ in chemistry and species in biology.

However, Bird and Tobin (2012) mentions that it is somewhat controversial to, for example, speak of natural kinds in biology concerning species - 
something traditionally thought unproblematic - and that it might be even more so in the social sciences, given that the particulars tend to be more dynamic. Just as regarding anthropomorphism, there is not one particular view that is fully embraced by the scientific community regarding natural kinds. Kornblith could once more be seen to downplay a debate that has far from reached a conclusive scientific consensus and instead presents his view concerning natural kinds, and knowledge as a natural kind, as less complicated than it is. ${ }^{5}$ There might be many acceptable ways to classify the world, and the same phenomenon in it, into kinds and perhaps still to regard them as natural kinds.

\subsection{Knowledge Requiring Reliably Produced True Belief (RTB)}

According to Kornblith we should look to cognitive ethology for an understanding of knowledge, and cognitive ethology tells us that:

"Knowledge explains the possibility of successful behavior in an environment, which in turn explains fitness. [... W]e must appeal to a capacity to recognize features of the environment, and thus the true beliefs that [... someone] acquire will be the product of a stable capacity for the production of true beliefs. The resulting true beliefs are not merely accidentally true; they are produced by a cognitive capacity that is attuned to its environment. In a word, the beliefs are reliably produced. The concept of knowledge which is of interest here thus requires reliably produced true belief." (Kornblith, 2002, pp. 57-58)

Kornblith's interpretation of cognitive ethology leads him to the following claim:

(9): "Knowledge is a robust category in the ethology literature; it is more than belief, and more than true belief. It requires reliably produced true belief." (Kornblith, 2002, p. 69)

Even though I consider the following claim in need of further discussion, which I will present below, Kornblith explicitly states:

5 Bermúdez (2006) points out cases where cognitive ethologists disagree with Kornblith's main tenets and about the possibility of using knowledge as a natural kind. I do not question Bermúdez in his argumentation and examples regarding other interpretations of how cognitive ethology should be viewed. But as concerning the previous point of anthropomorphism there is no general interpretation of the results from cognitive ethology that is totally conclusive and accepted by the majority of research, so I do not think that this is enough to pose a real threat to Kornblith's theory. 
(10): "The conception of knowledge that we derived from cognitive ethology literature, a reliabilist conception of knowledge, gives us the only viable account of what knowledge is." (Kornblith, 2002, p. 135, my italics)

Tying together all previously mentioned claims, (1)-(10), I argue that we arrive at the following conclusion:

$(i)$ : Reliabilist knowledge, requiring $R T B$, is the only viable account of what knowledge is.

Above I have tried to present and discuss Kornblith's naturalistic epistemological theory as a framework consisting of ten claims and a conclusion regarding what knowledge is. Claim (3) does stand out from the other claims in that it is normative. As previously mentioned, my interpretation of Kornblith's theory is that it promotes a cooperative naturalistic stance about how epistemology - and philosophy - ought to be conducted, which affects how we ought to view knowledge.

\section{An Issue Concerning the Sole Focus on Cognitive Ethology}

Kusch (2005) raises an issue that is genuinely problematic for Kornblith's theory. This issue, in my view, is so serious that Kornblith's theory in its present state should be abandoned. That said, I find that Kornblith's theory has so many fruitful aspects and strengths that it is worthwhile to consider possible revisions. In short, Kusch points out that it seems questionable to let cognitive ethology give us the only viable account of what knowledge is, when other sciences see knowledge in other ways:

"Kornblith rightly insists that the best way to find out about knowledge is to turn to scientific enquiry. He writes: 'Where should we turn, and how should we proceed, if we are to investigate the phenomenon of knowledge itself? ... One of the most fruitful areas of such research is cognitive ethology. ...' (28). Unfortunately, it turns out that this is the only area of 'such research' to which Kornblith pays attention. A critical reader cannot but wonder why cognitive ethology receives this special position. [...] Which account of knowledge should we favour: the account offered by cognitive ethology or the account proposed by the sociology of scientific knowledge? I see no reason to prefer one over the other." (Kusch, 2005, pp. 414-415) ${ }^{6}$

\footnotetext{
6 Kornblith actually writes that cognitive ethology is 'One of the more fruitful areas [...]' (Kornblith, 2002, p. 28, my italics).
} 
The sociology of scientific knowledge, upon which Kusch's criticism focuses, is a scientific field that investigates science as a social phenomenon. It is closely related to both sociology and the sociology of knowledge and emphasizes social factors and the cultural context surrounding a research paradigm, presented and discussed by Shapin (1995) and others. Kusch argues that knowledge, from the perspective of the sociology of scientific knowledge, might be viewed as a social kind. Since Kornblith's theory is a version of naturalistic realism and the sociology of scientific knowledge relates more readily with anti-realism, the two theories can be seen as endorsing two quite different stances.

Kornblith (2005, see also 2006) presents a reply to Kusch, discussing why cognitive ethology's take on knowledge is preferable to that of the sociology of scientific knowledge, also addressing other criticisms raised by Kusch. But regardless of whether Kornblith's rebuttal of the sociology of scientific knowledge is accepted or not, he sidesteps the more overarching issue regarding why sciences other than cognitive ethology should be disallowed. Even if Kornblith's stance is adopted, and cognitive ethology is seen as preferable to the sociology of scientific knowledge, the step from seeing cognitive ethology as one possible science of interest to it being the only one is not properly motivated - in the original text or in his reply to Kusch. Kornblith does not, for example, investigate how different sciences closer to his naturalistic realistic stance invoke knowledge. In his argumentation regarding human and animal knowledge, discussed in section 2.2 above, Kornblith briefly mentions how lower-level explanations of intentional phenomena risks missing central aspects that higher-level explanations are better suited to deal with, by abstracting away from physical details (Kornblith, 2002, pp. 39-41; see also Kornblith 1993, pp. 54-57). An anti-reductionist position regarding higherlevel theories about natural phenomena such as knowledge, might allow us to abstract away from (some) physical micro-details in certain contexts, but this would arguably not by itself make all lower-level sciences illegitimate. To let philosophy - or epistemology - be the arbiter of which sciences we should take seriously or not seems to be at odds with the cooperative naturalistic stance, and is something Kornblith explicitly warns against (Kornblith, 2002, p. 32). ${ }^{7}$ Nothing in Kornblith's line of reasoning indicates why we should ignore or invalidate all sciences other than cognitive ethology. What can be assessed is that (10), the claim that cognitive ethology gives us the only viable account of knowledge, is not convincingly motivated.

\footnotetext{
7 I will reconnect to this point in section 5.
} 


\section{Knowledge within Cognitive Neuroscience}

In this section I will focus on another scientific field in which knowledge plays an essential role, apart from cognitive ethology and the sociology of scientific knowledge, namely cognitive neuroscience. I will show that knowledge is used as a category that plays a causal and explanatory role within this field as well, which lies closer to cognitive ethology than the sociology of scientific knowledge. The significance of this discussion is that the constraints that Kornblith puts on knowledge in (10) become even more questionable: the issue concerning the sole focus on cognitive ethology remains even if knowledge is seen as a natural rather than a social kind.

According to cognitive neuroscience - a diverse field studying the biological foundations of cognitive processes - people are considered to get information from their senses, whereas the information is comprehended only after a complex combination of processes that leads to perceptions (for a comprehensive overview see, e.g., Bickle, 2009). This means that we cannot directly understand information that reaches our sense organs, which in itself is not comprehensible to us. Rather, we need to process the information that reaches us before the information becomes meaningful perceptions from which we can reason and act (Gazzaniga, Ivry and Mangun, 2002; see also Friston, 2009, 2010).

Long-term memory (LTM) is conventionally seen as the most relevant function(s) of the brain for the analysis of knowledge. LTM is commonly divided into the nested categories procedural memory, semantic memory and episodic memory (see, e.g., Tulving, 1985), and is thought to be able to handle a, practically speaking, infinite amount of information. LTM is grouped into two main categories: non-declarative (or implicit, non-accessible) memory, and declarative (or explicit, accessible) memory. Non-declarative procedural memory, beyond our conscious reach, handles our ability to perform actions, whereas consciously aware declarative semantic memory handles categorizations and concepts, and episodic memory handles remembered events and facts. Knowledge is in the traditional philosophical debate commonly divided into procedural knowledge and propositional knowledge, which in the cognitive neuroscientific terminology maps to procedural memory and episodic memory respectively. The examples below will however focus on conceptual knowledge, which maps to semantic memory.

To show that knowledge plays a causal and explanatory role in cognitive neuroscience, I will cite what I consider to be representative passages from cognitive neuroscientific texts. Pursuing clarity, I will only focus on semantic memory and conceptual knowledge. However, a similar presentation could easily be given concerning procedural memory and procedural knowledge or 
concerning episodic memory and propositional knowledge. More detailed arguments and discussions concerning different specific neuroscientific theories can be found in for example Churchland (1986), Bennett and Hacker (2003) and Bennett, Dennett, Hacker and Searle (2007).

In the words of Gazzaniga et al., semantic memories are described as:

"World knowledge, object knowledge, language knowledge, conceptual priming." (Gazzaniga et al., 2002, p. 314)

Connecting semantic memory with knowledge, Ward writes that:

"Semantic memory is conceptually based knowledge about the world, including knowledge of people, places, the meaning of objects and words. It is culturally shared knowledge. By contrast, episodic memory refers to memory of specific events in one's own life. The memories are specific in time and place. For example, knowing that Paris is the capital of France is semantic memory, but remembering a visit to Paris or remembering being taught this fact is episodic memory." (Ward, 2010, p. 186)

Patterson, Nestor and Rogers (2007) give the following description of semantic memory and knowledge:

"Semantic memory (also called conceptual knowledge) is the aspect of human memory that corresponds to general knowledge of objects, word meanings, facts and people, without connection to any particular time or place." (Patterson et al., 2007, p. 976)

Binder and Desai (2011) give this account of semantic memory:

"[...] semantic memory is one of our most defining human traits, encompassing all the declarative knowledge we acquire about the world. A short list of examples includes the names and physical attributes of all objects, the origin and history of objects, the names and attributes of actions, all abstract concepts and their names, knowledge of how people behave and why, opinions and beliefs, knowledge of historical events, knowledge of causes and effects, associations between concepts, categories and their bases, and on and on. [...] All of human culture, including science, literature, social institutions, religion, and art, is constructed from conceptual knowledge. We do not reason, plan the future or remember the past without conceptual content - all of these activities depend on activation of concepts stored in semantic memory." (Binder and Desai, 2011, p. 527)

Yee, Chrysikou and Thompson-Schill (2014) describe their view of semantic memory and knowledge: 


\begin{abstract}
"How do we know what we know about the world? For instance, how do we know that a cup must be concave, or that a lemon is normally yellow and sour? Psychologists and cognitive neuroscientists use the term semantic memory to refer to this kind of world knowledge. [...] Today, most psychologists use the term semantic memory [...] - to refer to all kinds of general world knowledge, whether it be about words or concepts, facts or beliefs. What these types of world knowledge have in common is that they are made up of knowledge that is independent of specific experiences; instead, it is general information or knowledge that can be retrieved without reference to the circumstances in which it was originally acquired." (Yee et al., 2014, p. 353)
\end{abstract}

As can be seen from this quote, and the next, it is possible to interpret Yee et al. as using semantic knowledge and semantic memory interchangeably. Furthermore, knowledge is used as a category to investigate the causal underpinnings of the memory system:

"Thus, the evidence suggests that semantic knowledge can be acquired independently of the episodic memory system. However, semantic knowledge in these amnesic patients is not normal (e.g., it is acquired very slowly and laboriously). It is therefore possible that the acquisition of semantic memory normally depends on the episodic system, but other points of entry can be used (albeit less efficiently) when the episodic system is damaged. Alternatively, these patients may have enough remaining episodic memory to allow the acquisition of semantic knowledge (Squire and Zola, 1998)." (Yee et al., 2014, p. 354)

So, knowledge does indeed play a causal and explanatory role in cognitive neuroscience - as it does in cognitive ethology. But, cognitive ethology has an ultimate focus on why a behavior occurs and on what animals should do, whereas cognitive neuroscience has a proximate focus on how animals do what they do (Scott-Phillips, Dickins and West, 2011; Martin and Bateson, 2007; Tinbergen, 1963). This divergence leads to a situation where knowledge as understood in cognitive ethology requires reliably produced true belief (9), whereas knowledge as understood in cognitive neuroscience is LTM

Elaborating on this divergence, and speaking against the compatibility of the two perspectives, the unreliability of human cognition and memory can be pointed out. For example, Tversky and Kahneman $(1971,1974)$ show how people tend to consistently make errors in their representations and inferences in some situations. These, and similar findings (see, e.g., Nisbett and Borgida, 1975; Ross, Lepper and Hubbard, 1975), indicates that LTM does in fact not readily provide reliable true belief, and that knowledge hence can not be seen as requiring this, since LTM is knowledge, from a cognitive neuroscientific perspective. LTM might sometimes and under certain circumstances provide reliable true belief, but at other times, and under other circumstances, this might not be the case. 
An argument supporting Kornblith's position indicating compatibility between reliable true belief and LTM might instead emphasize how the above point only applies in contrived situations and that animals (including humans) have an evolutionarily grounded tendency to come out right in their generalizations and predictions:

"Knowledge may never be absolute and certain, but it is always true enough to be workable." (Plotkin, 1993, p. 121)

However, even if the two sciences are seen as compatible, my point is that the two perspectives do diverge in important ways and that it is untenable to only allow the ultimate perspective as a base for giving us a viable account of what knowledge is. From a naturalistic perspective, as pointed out in section 3 , it is not the role of philosophy to pit different sciences against each other or to judge which sciences we should dismiss or follow, making Kornblith's claim (10) insupportable. ${ }^{8}$

\section{The Pluralism of Science}

There are actually a number of interconnecting sciences inquiring into animal cognition, and hence at least potentially into 'knowledge,' for example, cognitive neuroscience, developmental psychology, neurobiology, cognitive psychology, cognitive ethology, behavioral ecology, evolutionary psychology, evolutionary biology and cognitive zoology. However, for the purposes of the present argumentation it suffices to note that cognitive neuroscience belongs to this group.

Dupré (1993) argues that science cannot be seen as a unified project, since the world consists of such overwhelming pluralistic diversity. Any phenomenon is, according to Durpé, possible to reduce to multiple different natural kinds, depending on the context and goal that is seen as relevant (Dupré, 1993, pp. 1-5). What is to be considered a natural kind therefore depends on context, which in turn hinges on the goals of an investigator. Focusing on Kornblith's theory, it can only be said to identify knowledge as

\footnotetext{
8 An argument for the priority of cognitive ethology over cognitive neuroscience might be found in the thesis of multiple realizability, where cognitive ethology can be interpreted as better equipped to explain what knowledge is given its more functionalistic ultimate perspective. However, if the differences between humans and other animals are made salient, the same thesis can just as well be used against Kornblith's earlier merging of human and animal knowledge, and instead be interpreted as pointing out the importance of species-specific differences.
} 
a natural kind given a particular context and goal. From this perspective, Kornblith is in effect unreasonably excluding the possibility that other sciences could investigate the phenomenon from their particular context and with their goals.

A similar, albeit distinctly different, position is offered by Horst (see, e.g., 2011, 2016), who points out that all scientific models have some degree of idealization and abstraction built into them. The diversity and disunity Dupré ascribes to the world could thus instead be interpreted as a result of disunities in how we model the world (Horst, 2011, p. 69):

"[... T] he mind employs a plurality of mental models, [...] each idealized in form, and consequently [...] scientific models of any of these mental models must be viewed as partial and idealized." (Horst, 2011, p. 254)

Horst offers an interesting framework for scientific theories and models, which he calls 'cognitive pluralism:'

"Within a Cognitive Pluralist framework, however, we can see these as variations on a theme rather than as essential differences. All models are plural, partial, idealized, and cast in some particular representational system. Scientific models are particularly regimented and formally exact. And within the class of scientific models we find different types of idealization conditions that result in closer or more distant relationships between models and the real-world behavior that they are invoked to explain." (Horst, 2011, p. 261)

Just how we model a natural phenomenon, such as knowledge, will thus hinge on which science we use, without necessarily saying anything about the underlying properties - diverging models are possible of the same natural kind. In other words we can investigate and try to "triangulate" the same natural kind - the homeostatically clustered properties forming a well-behaved category - by looking at it through different "lenses," which all might skew our view in idiosyncratic ways resulting in diverging accounts of the same phenomenon (see, e.g., Horst, 2016, p. 83).

In fact, support for a pluralistic way of thinking about natural kinds can be found in Kornblith's own work:

"Not just any scheme of classification corresponds to the real kinds in nature. It is just that the structure of the real kinds may not be as simple or as neat as has been dreamt of in many philosophies. The homeostatic cluster account thus suggests a rich overlapping structure of kinds in nature, with the various sciences picking out families of kinds which are interrelated." (Kornblith, 1993, p. 52)

The step from granting that different sciences pick out families of kinds that are interrelated to granting that this is so in the case of knowledge is very 
short indeed. Scientific pluralism and theoretical unity can on such an account, in my view, be seen as compatible. Knowledge can hence be interpreted as to consist of a slightly more inclusive overlapping and interrelated structure than is ordinarily assumed. The various sciences' accounts of the natural kind will accordingly be affected by their particular "lens" and be more or less commensurable (Horst, 2016, pp. 7, 222-226). ${ }^{9}$

As previously mentioned, the different sciences relevant in regards to animal cognition focus on partly different aspects, or points of view; for example, cognitive neuroscience, developmental psychology, neurobiology and cognitive psychology have a proximate focus on how animals do what they do, whereas cognitive ethology, behavioral ecology and evolutionary psychology have an ultimate focus on why a behavior occurs and what animals should do (Scott-Phillips et al., 2011). Scott-Philips et al. points out the importance of clearly stating the framework from within which one works, and the possibility of investigating the same phenomenon from multiple points of view.

The above ideas regarding pluralism and the importance of different points of view can be given a firmer standing with the help of the concept of 'levels.' The world can be investigated at different levels, for example from the perspective of: physics, chemistry, cellular biology, functional biology, psychology, sociology, and so on. To illustrate the different "middle-range" levels, and how they affect our view of knowledge, at least four different sciences come readily to mind: cognitive neuroscience, cognitive psychology, the sociology of scientific knowledge and cognitive ethology. Of these four levels Kornblith favors the latter, Kusch favors the third and I have discussed the first above. But in all of the above-mentioned scientific fields it can be argued that knowledge plays an important role - just as it does in cognitive ethology - and is treated as a phenomenon with theoretical unity. The key issue here is, in my view, whether one favors a more traditional top-down approach focusing on "higher" functions, in which case cognitive ethology is a natural choice of science to focus on. If one, on the other hand, favors a bottom-up approach focusing on how the "lower" levels affect the higher ones, cognitive neuroscience is an interesting candidate. LTM could then be seen as knowledge on a cognitive neuroscientific level of explanation, and as the underlying microstructure for knowledge (RTB) on the higher cognitive ethological level of explanation. ${ }^{10}$

\footnotetext{
9 If this is not taken into account theoreticians risk talking past each other.

${ }^{10}$ A contrasting opinion and discussion can be found in for example Horvath (2016, pp. 175-176).
} 
A more inclusive version of claim (6) thus ought to be introduced, that allows for all relevant sciences to be used in an investigation:

(6i): Knowledge plays a causal and explanatory role within several of our more fruitful current theories.

As the previous discussion has shown, it is relevant to take context and goals, point of view, and level of explanation into account while investigating knowledge. Depending on how one chooses to position oneself concerning these matters, investigations will take different forms and different sciences will be more or less relevant. To enable a pluralistic revision of Kornblith's theory the following claim should thus be added:

(11): Philosophical investigations ought to adopt a stance accommodating scientific pluralism.

\section{Revising Kornblith's Theory}

From the above discussion it should be clear that at least cognitive neuroscience is a legitimate science in which knowledge plays an essential role, and yet its account of what knowledge is diverges from the account found in cognitive ethology, regarding context, goals, focus and level of explanation. Kornblith's claim that cognitive ethology gives us the only viable account of knowledge is thus not plausible. Kornblith's theory needs to be revised, along the lines already proposed, in order to save the theory from the issue concerning the sole focus on cognitive ethology.

To be concrete, Kornblith needs to retract claim (10) as well as conclusion $(i) .{ }^{11}$ What then follows is that reliabilist knowledge, requiring RTB, is one viable account of what knowledge is. This is a plausible conclusion given that one's focus is on cognitive ethology. However, if we replace (6) by $(6 i)$, as previously hinted, and add claim (11) while removing claims (7) and (9), what we get is the kind of pluralism which our argument has led us to:

(1): The subject matter of epistemology is knowledge itself, not our concept of knowledge.

(2): Theoretical understanding trumps intuitive judgment, so intuitions should give way to theoretical understanding based on empirical investigations of external phenomena.

\footnotetext{
${ }^{11}$ Bermúdez mentions similar concerns, but sees the situation facing Kornblith's theory as risking it being dubbed folk psychology rather than focusing on the possibility of an inclusive pluralism (Bermúdez, 2006, p. 304).
} 
(3): Philosophical investigations ought to adopt a cooperative naturalistic stance.

(4): Human knowledge is a natural phenomenon.

(5): The natural phenomenon of human knowledge has a good deal of theoretical unity.

(6i): Knowledge plays a causal and explanatory role within several of our more fruitful current theories.

(8): Knowledge is a natural kind.

(11): Philosophical investigations ought to adopt a stance accommodating scientific pluralism.

The theory thus outlined retains important insights of Kornblith's theory while, at the same time, saving that theory from the issue concerning the sole focus on cognitive ethology.

\section{Conclusion}

I addressed Hilary Kornblith's proposal that knowledge is a natural kind, the identification of which is the unique responsibility of one particular science: cognitive ethology. As Kornblith sees it, the natural kind thus picked out is knowledge as construed by reliabilism. I have argued that knowledge plays a causal and explanatory role within many of our more fruitful current theories, diverging from the reliabilist conception even in disciplines that are closely related to cognitive ethology, focusing on cognitive neuroscience. Rather than discarding the natural kind approach altogether, as some authors have been tempted to do, I proposed that many of Kornblith's insights can in fact be preserved within a framework that is both naturalist and pluralist. In this way Kornblith's naturalistic epistemology, in its revised pluralist form, can remain a promising and fruitful framework for investigating knowledge - indeed as a natural kind.

\section{Acknowledgements}

I am very grateful to Erik J. Olsson for his guidance, helpful comments and for him being extremely charitable with his knowledge and time. Thanks to Johannes Persson, Shira Singer and my anonymous referees for comments. 


\section{References}

Bennett, M., Dennett, D., Hacker, P. and Searle, J. (2007). Neuroscience and Philosophy: Brain, Mind, and Language. New York: Columbia University Press.

Bennett, M. R. and Hacker, P. M. S. (2003). Philosophical Foundations of Neuroscience. Malden, MA: Blackwell Publishers.

Bermúdez, J. L. (2006). 'Knowledge, Naturalism, and Cognitive Ethology: Kornblith's Knowledge and its Place in Nature', Philosophical Studies, 127: $299-316$.

Bickle, J. (ed.) (2009). The Oxford Handbook of Philosophy and Neuroscience. Oxford: Oxford University Press.

Binder, J. R. and Desai, R. H. (2011). 'The Neurobiology of Semantic Memory', Trends in Cognitive Sciences, 15(11): 527-536.

Bird, A. and Tobin, E. (2012). 'Natural Kinds', In E. N. Zalta (ed.), The Stanford Encyclopedia of Philosophy (Winter 2012 Edition). http://plato.stanford.edu/archives/win2012/entries/natural-kinds/

Bonjour, L. (1985). The Structure of Empirical Knowledge. Cambridge, MA: Harvard University Press.

Chisholm, R. M. (1988). 'The Indispensability of Internal Justification', Synthese, 74: 285-296.

Churchland, P. M. and Churchland, P. S. (1998). On the Contrary: Critical Essays 1987-1997. Cambridge, MA: The MIT Press.

Churchland, P. S. (1986). Neurophilosophy: Toward a Unified Science of the Mind-Brain. Cambridge, MA: The MIT Press.

Dennett, D. (1996). The Intentional Stance. Cambridge, MA: The MIT Press.

Dewey, J. (1938). Logic: The Theory of Inquiry. New York: Holt, Rinehart and Winston.

Dretske, F. (1981). Knowledge and the Flow of Information. Cambridge, MA: The MIT Press.

Dupré, J. (1993). The Disorder of Things: Metaphysical Foundations of the Disunity of Science. Cambridge, MA: Harvard University Press.

Friston, K. (2009). 'The Free-Energy Principle: A Rough Guide to the Brain?', Trends in Cognitive Sciences, 13(7): 293-301.

Friston, K. (2010). 'The Free-Energy Principle: A Unified Brain Theory?', Nature Reviews Neuroscience, 11(2): 127-138.

Gazzaniga, M. S., Ivry, R. B. and Mangun, G. R. (2002). Cognitive Neuroscience: The Biology of the Mind. New York: W. W. Norton and Company. 
Goldman, A. I. (1986). Epistemology and Cognition. Cambridge, MA: Harvard University Press.

Goldman, A. I. (2005). 'Kornblith's Naturalistic Epistemology', Philosophy and Phenomenological Research, 71(2): 403-410.

Horst, S. (2011). Laws, Mind, and Free Will. Cambridge, MA: The MIT Press.

Horst, S. (2016). Cognitive Pluralism. Cambridge, MA: The MIT Press.

Horvath, J. (2016). 'Conceptual Analysis and Natural Kinds: The Case of Knowledge', Synthese, 193(1): 167-184.

James, W. (1907 [1995]). Pragmatism: A New Name for Some Old Ways of Thinking. New York: Dover.

Kim, J. (1988). 'What is 'Naturalized Epistemology'?', Philosophical Perspectives, 2: 381-405.

Klopfer, P. H. (2005). 'Animal Cognition and the New Anthropomorphism', International Journal of Comparative Psychology, 18(3): 202-206.

Kornblith, H. (1993). Inductive Inference and Its Natural Ground: An Essay in Naturalistic Epistemology. Cambridge, MA: The MIT Press.

Kornblith, H. (2002). Knowledge and its Place in Nature. Oxford: Oxford University Press.

Kornblith, H. (2005). 'Replies to Alvin Goldman, Martin Kusch and William Talbott', Philosophy and Phenomenological Research, 71 (2): 427-441.

Kornblith, H. (2006). 'Reply to Bermúdez and BonJour', Philosophical Studies, 127: 337-349.

Kornblith, H. (2012). On Reflection. Oxford: Oxford University Press.

Kusch, M. (2005). 'Beliefs, Kinds and Rules: A Comment on Kornblith's Knowledge and Its Place in Nature', Philosophy and Phenomenological Research, 71(2): 411-419.

Maddy, P. (2007). Second Philosophy: A Naturalistic Method. Oxford: Oxford University Press.

Martin, P. and Bateson, P. (2007). Measuring Behaviour. Cambridge: Cambridge University Press.

Nisbett, R. E. and Borgida, E. (1975). 'Attribution and the Psychology of Prediction', Journal of Personality and Social Psychology, 32(5): 932943.

Papineau, D. (2015). 'Naturalism', In E. N. Zalta (ed.), The Stanford Encyclopedia of Philosophy (Fall 2015 Edition). http://plato.stanford.edu/archives/fall2015/entries/naturalism/

Patterson, K., Nestor, P. J. and Rogers, T. T. (2007). 'Where do You Know what you Know? The Representation of Semantic Knowledge in the Human Brain', Nature Review Neuroscience, 8: 976-987. 
Peirce, C. S. (1877 [1955]). 'The Fixation of Belief', In J. Buchler (ed.), Philosophical Writings of Peirce (pp. 5-22). New York: Dover Publications, Inc.

Plotkin, H. C. (1993). Darwin Machines and the Nature of Knowledge. Cambridge, MA: Harvard University Press.

Quine, W. V. O. (1969). 'Epistemology Naturalized', In Ontological Relativity and Other Essays (pp. 69-90). New York: Columbia University Press.

Ross, L., Lepper, M. R. and Hubbard, M. (1975). 'Perseverance in selfperception and social perception: Biased attributional processes in the debriefing paradigm', Journal of Personality and Social Psychology, 32: 880-892.

Rysiew, P. (2016). 'Naturalism in Epistemology', In E. N. Zalta (ed.), The Stanford Encyclopedia of Philosophy (Summer 2016 Edition). http://plato.stanford.edu/archives/sum2016/entries/epistemology-naturalized/

Scott-Phillips, T. C., Dickins, T. E. and West, S. A. (2011). 'Evolutionary Theory and the Ultimate-Proximate Distinction in the Human Behavioral Sciences', Perspectives on Psychological Science, 6(1): 38-47.

Shapin, S. (1995). 'Here and Everywhere: Sociology of Scientific Knowledge', Annual Review of Sociology, 21: 289-321.

Shettleworth, S. J. (2013). Fundamentals of Comparative Cognition. Oxford: Oxford University Press.

Siegel, H. (2006). 'Book Review: Hilary Kornblith, Knowledge and its Place in Nature', Philosophical Review, 115(2): 246-251.

Tinbergen, N. (1963). 'On Aims and Methods of Ethology', Zeitschrift für Tierpsychologie, 20: 410-433.

Tulving, E. (1985). 'Memory and Consciousness', Canadian Psychology, 26(1): 1-12.

Tversky, A. and Kahneman, D. (1971). 'Belief in the Law of Small Numbers', Psychological Bulletin, 76(2): 105-110.

Tversky, A. and Kahneman, D. (1974). 'Judgment under Uncertainty: Heuristics and Biases', Science, New Series, 185(4157): 1124-1131.

van Fraassen, B. C. (2002). The Empirical Stance. London: Yale University Press.

Ward, J. (2010). The Student's Guide to Cognitive Neuroscience. New York: Psychology Press.

Wynne, C. D. L. (2007). 'What are Animals? Why Anthropomorphism is still not a Scientific Approach to Behavior', Comparative Cognition and Behavior Reviews, 2: 125-135.

Yee, E., Chrysikou, E. G. and Thompson-Schill, S. L. (2014). 'Semantic Memory', In K. Ochsner and S. Kosslyn (eds), The Oxford Handbook of 
Cognitive Neuroscience: Volume 1, Core Topics (pp. 353-374). Oxford: Oxford University Press. 